\title{
BARGANHA DO SERVIÇO PÚBLICO: ESTADO DA ARTE E AGENDA DE PESQUISA
}

\author{
PUBLIC SERVICE BARGAIN: STATE OF THE ART AND RESEARCH AGENDA
}

\section{Luan Bernardo Lima}

Universidade Federal do Espírito Santo (UFES), Vitória/ES, BRASIL

bernn.lima@gmail.com

\section{Resumo}

A aliança ou o pacto entre Política e Administração é considerado essencial para o funcionamento das instituições públicas, compondo um tema clássico da Administração Pública e sendo objeto de estudos empíricos expressivos no âmbito internacional. $\mathrm{Na}$ academia brasileira, contudo, esta temática tem sido abordada de maneira esporádica sob o aspecto empírico. Diante deste cenário, este artigo apresentou a Barganha do Serviço Público, abordagem teórica que compreende a relação político-administrativa como uma troca entre recompensas econômicas e intangíveis dada aos servidores públicos em troca de certas competências e fidelidade pactuada com os políticos eleitos, e revisou a produção acadêmica que a utilizou por meio das bases de dados Scopus e Web of Sciences. Dessa forma, este artigo buscou situar esta abordagem como um suporte analítico relevante a fim de investigar a administração pública e o governo brasileiro, analisando os estudos selecionados mediante as características contextuais, metodológicas, teóricas e quanto aos resultados de pesquisa. Assim, por meio do estado da arte e das conclusões realizadas, foram desenvolvidas proposições para uma agenda de pesquisa no contexto brasileiro.

Palavras-chave: Administração Pública. Relações Político-Administrativas. Barganha do Serviço Público. New Public Management.

\begin{abstract}
The alliance or the pact between Politics and Administration is considered essential for the functioning of the public institutions, composing a classic theme of the Public Administration and being object of ample empirical studies in the international scope. In the Brazilian academy, however, this theme has been approached sporadically under the empirical aspect. Given this scenario, this article presented the Public Service Bargain, a theoretical approach that understands the political-administrative relationship as an exchange between economic and intangible rewards given to public servants in exchange for certain competencies and fidelity agreed upon with elected politicians, and revised the academic production that used it through the Scopus and Web of Sciences databases. Thus, this article sought to situate this approach as a relevant analytical support in order to investigate the Brazilian public administration and the Brazilian government, analyzing the selected studies through the respective contextual, methodological, theoretical and research results. Thus, through the state of the art and the conclusions reached, proposals were developed for a research agenda in the Brazilian context.
\end{abstract}

Keywords: Public Administration. Political-Administrative Relationships. Public Service Bargaining. New Public Management. 


\section{Introdução}

O relacionamento entre o sistema político e os servidores públicos é um tema expressivo na literatura internacional no âmbito da Administração Pública, destacando-se os estudos seminais de Putnam (1976), Aberbach, Putnam e Rockman (1981) e Svara (1985; 1999), e sendo a interface constituída pela estrutura essencial do governo, ou seja, pelos políticos eleitos, fruto do processo de representação democrática, e pelos servidores públicos, tanto temporários quanto permanentes. Orientado em compreender o papel de cada domínio no governo, as investigações empíricas têm examinado as funções desempenhadas por cada parte, os valores e perspectivas que circunscrevem diferentes maneiras de se lidar com o Estado, as formas de interação decorrentes e as respectivas implicações para as instituições e políticas públicas. Com as influências da New Public Management (NPM), notase a incorporação desta temática a fim de examinar a natureza das transformações da administração pública, emergindo como corrente profícua e recente o entendimento das relações político-administrativas como barganhas ou acordos explícitos e implícitos entre o sistema político e o serviço público do Poder Executivo (HOOD, 2000; 2001; 2002; HOOD; LODGE, 2006).

Originado como forma de entender os paradoxos presentes na NPM, Hood (2000; 2001; 2002) concebeu os interesses, vantagens e oportunidades do sistema político e do serviço público nas reformas empreendidas, condicionando, de certa forma, a diversidade de implementação em diferentes contextos. Concebido pela entrega de uma esfera de autoridade e de retribuições monetárias para os servidores públicos (recompensa) em troca de certa habilidade (competência) e compromisso estabelecido (lealdade ou responsabilidade) em contrapartida aos atores políticos (HOOD; LODGE, 2006), a análise das barganhas têm se mostrado relevante visto estar orientada ao entendimento do núcleo do governo e da administração pública através das interações estratégicas entre os atores e do legado histórico das relações. Destaca-se, assim, ao ir além dos aspectos técnicos e gerenciais, estando vinculada a análise dos aspectos institucionais e das relações de poder.

Os estudos sobre a administração pública brasileira, embora enfoquem o papel do Estado na sociedade sem incorporar a interface com o sistema político (LOUREIRO; ABRUCIO; PACHECHO, 2010), tem explorado este tema contemplando os critérios de nomeação para altos cargos da administração federal (GOMES, 2016; LOPEZ, 2015; LOUREIRO; ABRUCIO, 1999; OLIVIERI, 2007; PRAÇA; FREITAS; HOEPERS, 2011), a composição e divisão de trabalho das elites governantes ${ }^{1}$ (CODATO, 2009; CODATO; CAVALIERI; PERISSINOTTO; DANTAS, 2016; D'ARAUJO, 2009; 2014) e o controle político sobre a burocracia (OLIVIERI, 2010). Além disso, alguns estudos referem-se de maneira tangencial ao tema, emergindo aspectos da intermediação político-administrativa, por exemplo, ao examinar o papel dos burocratas de nível médio, (CAVALCANTE; LOTTA, 2015; OLIVEIRA; ABRUCIO, 2011; OLIVEIRA; FILHO, 2017). Deste modo, ao identificar em referência ao contexto brasileiro a limitação dos tópicos investigados e a ausência de estudos que utilizem o entendimento desta interface como barganhas, definiu-se como objetivo deste artigo desenvolver o estado da arte desta abordagem como contribuição.

Sobre o contexto brasileiro, de forma específica, são evidenciadas as influências da NPM pela implementação no nível federal da Reforma de Estado em 1995, tendo impactado as instituições públicas e o acordo político-administrativo por meio de reformas e medidas de austeridade. Neste movimento, decorreram revisões e mudanças nos salários, promoções, sistemas de carreira, aposentadorias e sistemas de avaliação. Dessa forma, e incluindo as influências que culminaram em diferentes reformas aplicadas também nos níveis estadual e municipal (ABRUCIO, 2007; DE ARAÚJO; PEREIRA, 2012; TORRES, 2004), coloca-se como oportuno o entendimento das barganhas político-administrativas a fim de elucidar o papel das interações estratégicas entre os atores nas transformações e rupturas decorrentes dessas repactuações, sendo relevante para a compreensão das influências gerenciais na administração pública brasileira. Além disso, a conjuntura de crise econômica e institucional instalada, análoga ao da década de 1990, tem possibilitado a retomada dos discursos e reformas gerenciais, sobressaindo-se a importância de investigar este fenômeno em curso por uma nova abordagem.

\footnotetext{
P> Destaca-se que o estudo das elites políticas no Brasil, em específico, é uma área mais ampla, também abordando o papel das elites na mudança de regime, tendo como premissa que as escolhas das elites influenciam as rupturas institucionais (ARAYA, 2018), e o relacionamento entre o executivo e o legislativo, centrando-se no processo de decisão no Congresso Nacional (FIGUEIREDO; LIMONGI, 2001).
} 
Dessa maneira, foi realizado o estado da arte dos estudos realizados nesta perspectiva, sendo seguido por considerações para estudos futuros, pretendendose contribuir ao situar a abordagem de Hood e Lodge (2006) como possibilidade teórico-metodológica de investigação das relações entre Política e Administração no contexto brasileiro. Dessa forma, foi realizada uma revisão sistemática da literatura a partir de artigos científicos teóricos e empíricos publicados em periódicos nas bases Web of Science e Scopus, dado o caráter representativo destas na área, e colocando-se como focus de análise o contexto das publicações, as características teóricas e metodológicas e os resultados de pesquisa. Assim, a esta introdução sucede-se quatro seções; a síntese teórica da Barganha do Serviço Público; o detalhamento metodológico do estado da arte; a análise das publicações selecionadas; e, por fim, são expostas as conclusões do estudo e algumas proposições para o futuro da pesquisa no tema com foco no contexto brasileiro.

\section{Barganha do Serviço Público}

Schaffer (1973), ao analisar o relacionamento entre os políticos eleitos e os servidores públicos indicados na Inglaterra no começo do século XIX, notou que os primeiros recompensavam os segundos com a permanência no cargo em troca de que estes abdicassem de participar em atividades políticas e em criticar abertamente às políticas do governo, expondo a limitação da discricionariedade do serviço público ao mesmo tempo em que este pactuava a lealdade com a realeza. Hood (2000; 2001; 2002), tendo como origem esta concepção da interface, ou seja, como barganha ou acordo, identificou que as reformas gerenciais tiveram como condicionantes as barganhas políticoadministrativas precedentes, as quais restringiram e oportunizaram os motivos e oportunidades dos políticos e dos servidores públicos em cena, explicando como a NPM tem sido implementada de diferentes formas e graus. Dessa maneira, o autor estendeu a barganha schafferiana para outras formas, como o da subordinação político-administrativa do sistema de espólio dos Estados Unidos no século XIX, em que os servidores expressavam identidades políticas, mas, em contraponto, permaneciam no cargo apenas enquanto o partido ou político eleito que o indicasse subsistisse no governo.

A abordagem sistemática das relações políticoadministrativas como barganhas tomou corpo com a obra de Hood e Lodge (2006), com base em uma análise da experiência história e de pesquisas sociais realizadas com o auxílio das quatro visões de mundo da grid-group cultural theory (hierárquica, igualitária, individualista e fatalista), sendo os principais atributos sintetizados no Quadro 1:

Quadro 1. Principais Atributos da Barganha do Serviço Público

\begin{tabular}{|c|l|l|}
\cline { 2 - 3 } \multicolumn{1}{c|}{} & \multicolumn{1}{c|}{ Políticos } & \multicolumn{1}{c|}{$\begin{array}{c}\text { Servidores } \\
\text { Públicos }\end{array}$} \\
\hline Entrega & $\begin{array}{l}\text { Concede direitos } \\
\text { de contratar, } \\
\text { remunerar e demitir } \\
\text { Os servidores } \\
\text { públicos }\end{array}$ & $\begin{array}{l}\text { Concede direitos } \\
\text { de culpar ou se } \\
\text { opor ao governo } \\
\text { dominante }\end{array}$ \\
\hline & $\begin{array}{l}\text { Ganha a fidelidade } \\
\text { política e alguma } \\
\text { forma de } \\
\text { competência }\end{array}$ & $\begin{array}{l}\text { Ganha uma posição } \\
\text { no governo, área de } \\
\text { responsabilidade } \\
\text { e recompensas } \\
\text { tangíveis e } \\
\text { intangíveis }\end{array}$ \\
\hline
\end{tabular}

Fonte: Hood e Lodge (2006, p. 8, tradução nossa).

A Barganha do Serviço Público, assim, concebe as barganhas político-administrativas em dois tipos estruturantes, agência e curadoria, e três dimensões, recompensa, competência e lealdade ou responsabilidade (HOOD; LODGE, 2006). A agência, tal como demonstrado, caracteriza a interface em que há a subordinação do serviço público perante o sistema político, podendo se expressar de diferentes maneiras, como o modelo tradicional inglês, em que na mudança de governo o servidor permanece no cargo (lealista periódico), servindo um novo líder político, no sistema de espólio, "caindo e descendo" acompanhando o superior político (lealista pessoal) e, na influência gerencial, o controle por meio de metas e objetivos (delegada simples) (HOOD; LODGE, 2006). Na curadoria, por outra via, os servidores públicos operam como atores semiautônomos perante o sistema político, podendo ser ilustrado na figura do serviço civil hegeliano da Alemanha, com o caráter técnico (tecnocrática), no Chinês, caracterizado por entregar qualidades morais e culturais (moralista), sob a perspectiva do confucionismo, e o de formas representacionais, tal como no subtipo 
consociativo, no qual diferentes grupos sócias, tais como étnicos, raciais e religioso, ganham espaço e certa liberdade no serviço público, como demonstrado em muitos países da Europa Continental (HOOD; LODGE, 2006). Além disso, os autores destacamse que enquanto sob a barganha agência o sistema político é o detentor do controle sobre as recompensas, competências e o compromisso acordado, na curadoria o controle está relacionado a formas mais abrangentes, podendo a sociedade, por exemplo, reivindicar mudanças nos acordos.

Quanto às dimensões, a recompensa refere-se à seleção e permanência no cargo, e às retribuições monetárias e subjetivas dos servidores, enquanto a competência representa as habilidades demandadas destes pelo comando político. A lealdade ou responsabilidade, por sua vez, corresponde ao compromisso estabelecido pelo servidor em relação ao sistema político. De forma demonstrativa, pode-se descrever as dimensões por meio do tipo ideal gerencial concebido por Hood e Lodge (2006). Sobre este, os autores encaram que, caso a reforma gerencial fosse adotada de forma plena, apesar de considerar as divergências e contradições como este ideário é evocado, as recompensas mudariam da permanência vitalícia no cargo para formas mais flexíveis, como contratos com tempo estabelecido, os salário deixariam de ser fixos para a vinculação ao desempenho individual; a demanda de competências de assessoria nas políticas públicas e de julgamento político diminuiria para o aumento da habilidade de entrega de resultados; e a lealdade ou responsabilidade se moveria da ênfase de orientação em essências abstratas para o compromisso de subordinação limitado, circunscrito e executivo. De forma ampla, Hood e Lodge (2006) argumentam que a forma específica dos dois tipos, agência e curadoria, estruturam as relações entre os atores, beneficiando e incompatibilizando o acordo por competências, recpompensas e lealdades específicas. Estas categorias, por sua vez, ao se manifestarem em vários subtipos, comportam misturas e combinações.

\section{Procedimentos Metodológicos}

Considerando o objetivo de realizar o estado da arte desta teoria no campo de pesquisa, ou seja, de analisar os estudos que utilizam como fundamento a Barganha do Serviço Público, adotou-se a metodologia revisão sistemática da literatura, sendo a identificação, seleção e avaliação sistemática de um grupo de estudos. A partir das bases de dados Web of Sciences e Scopus, dado a relevância destas no cenário nacional e internacional no âmbito das áreas de Administração Pública, Governo e Ciência Política, cujas interseções compõem a arena de investigação da temática proposta, foram selecionados artigos empíricos e teóricos. A coleta dos dados, dessa maneira, foi efetuada por meio do nome de referência da abordagem de Hood e Lodge (2006), o termo "public service bargain", abrangendo a busca em títulos, resumos e palavras-chaves, totalizando-se em 55 artigos publicados em revistas acadêmicas e 2 capítulos de livro, selecionados a partir de 2006, data de publicação da obra de Hood e Lodge (2006). Ao eliminar as publicações duplicadas nas duas bases e as em fase de publicação, chegou-se ao número de 32 artigos e 2 capítulos de livro. De forma complementar, foram buscados estudos referenciados pelos artigos selecionados, possibilitando o acréscimo de 3 trabalhos, e totalizando, assim, em um grupo de 35 artigos e 2 capítulos de livro.

É importante destacar que a escolha por artigos publicados em periódicos acadêmicos foi a forma adotada de selecionar estudos maduros e com maior qualidade para a discussão científica. Além disso, salienta-se que apesar do termo de busca estar em língua inglesa, a orientação deste trabalho foi sistêmica, sendo possível por meio do termo definido selecionar artigos em outras línguas, como a francesa, a espanhola e a lituana.

A análise dos artigos selecionados foi orientada pelos seguintes critérios: a) contexto das publicações; b) características metodológicos; c) características teóricas; e, d) resultados das pesquisas. No primeiro critério, foram abordadas as publicações por meio da periodicidade ao longo do tempo, dos principais periódicos no tema, as áreas de conhecimento relacionadas e os países e regiões analisados por meio de seus níveis de análise. O segundo critério abarcou os tipos de pesquisas empreendidas (teóricas e empíricas), as abordagens utilizadas (qualitativas e quantitativas), as unidades de investigação (individual, grupal, organizacional e institucional), os recortes temporais (transversal, transversal com perspectiva longitudinal, e longitudinal) e os procedimentos de coleta e análise de dados. No terceiro, características teóricas, foram analisadas as formas que as barganhas foram estudadas, envolvendo as temáticas específicas investigadas por meio do relacionamento políticoadministrativas. Por fim, foram analisados os resultados das pesquisas em duas partes, a primeira, sobre os estudos teóricos, com ênfase especial para o 
foco verificado na busca do rompimento dos limites existentes da abordagem, e a segunda analisou as conclusões das pesquisas empíricas por meio da divisão em grupos comuns (Barganhas Nacionais, Barganhas Comparadas e Barganhas em Outros Contextos).

\section{Estado da Arte da Barganha do Serviço Público}

\section{Contexto das Publicações}

Nos primeiros três anos, iniciando-se no ano da publicação da obra de Hood e Lodge (2006), foi notado a presença de somente dois estudos (5\%); de 2009 a 2011, onze estudos (30\%); de 2012 a 2014, treze estudos (35\%); e, por fim, de 2015 a 2017, onze estudos (30\%), demonstrados na Figura 1. A quantidade reduzida da primeira fase explica-se, evidentemente, por conta do ineditismo do trabalho, crescendo progressivamente nas duas fases seguintes. A quarta e última fase, contudo, apresenta um decrescimento em relação à anterior de $15 \%$. Destaca-se na segunda fase o ano de 2011, com sete estudos (19\%), e na segunda fase o ano de 2013, com nove estudos (25\%). A quantidade expressiva destes dois anos explica-se pela publicação de edições especiais, tendo como foco o uso da Barganha do Serviço Público como forma de ir além dos aspectos técnicos e gerenciais quanto aos impactos das reformas administrativas recentes, como destacado por Hondeghem (2011) e Hondeghem e Steen (2013), contribuindo, além disso, ao aumentar as evidências empíricas e, assim, possibilitar colocar a capacidade explicativa da teoria em teste em outros contextos.

Figura 1. Contexto das Publicações

Periodicidade das Publicações

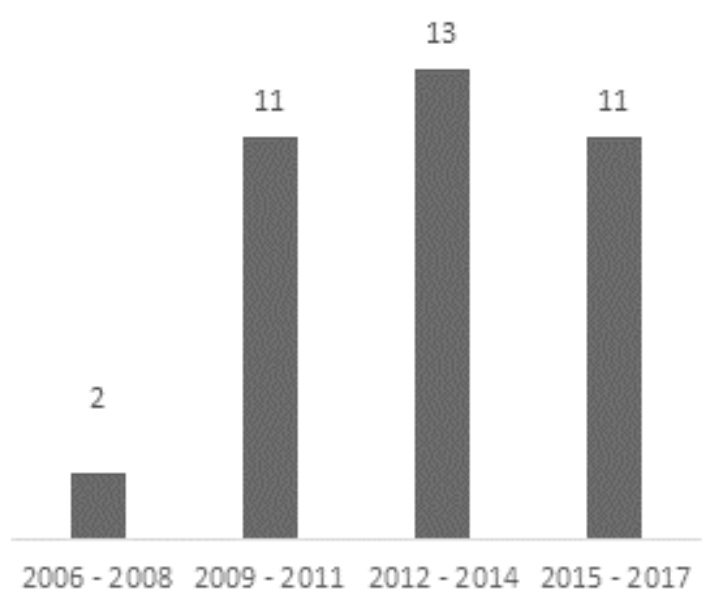

Perspectiva de Pesquisa

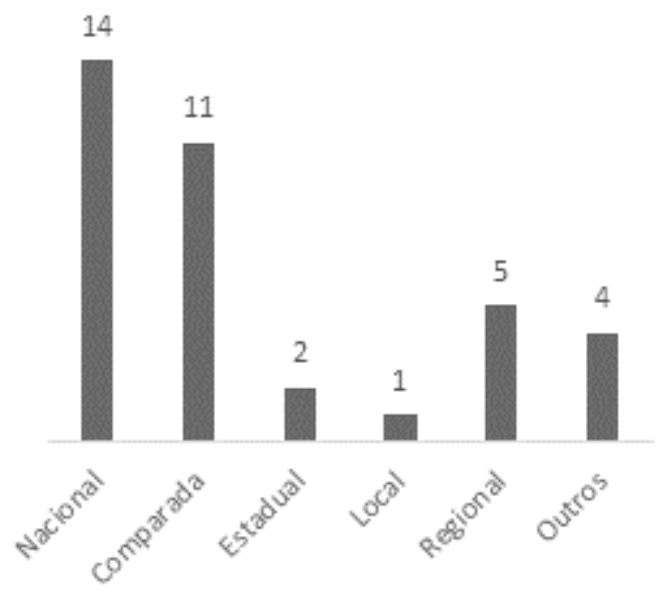

Fonte: Elaborado pelo autor.

Quanto aos periódicos acadêmicos, sobressaíram-se com a maior quantidade de publicações no tema o International Review of Administrative Sciences, da área de gestão e administração pública, e o Public Policy and Administration, da área de políticas públicas e administração pública, como demonstrado na Tabela 1. A concentração nestes dois periódicos é elucidada, primeiramente, por terem publicado, cada qual, uma das duas edições especiais. E isto, por sua vez, explica-se, de certa forma, por ambos possuírem como orientação a abertura para novas abordagens de estudo, dando espaço a teoria emergente. Por outro lado, ao adotarem uma perspectiva internacional, deram vazão aos estudos nacionais de diferentes contextos, além dos comparativos. 
Tabela 1. Barganha do Serviço Público nos Periódicos Acadêmicos

\begin{tabular}{|c|c|c|}
\hline Periódico & Área & Quantidade \\
\hline $\begin{array}{l}\text { International Review Of } \\
\text { Administrative Science }\end{array}$ & $\begin{array}{l}\text { Gestão e Adm. } \\
\text { Pública }\end{array}$ & 11 \\
\hline $\begin{array}{l}\text { Public Policy and } \\
\text { Administration }\end{array}$ & $\begin{array}{c}\text { Políticas Públicas e } \\
\text { Adm. Pública }\end{array}$ & 5 \\
\hline Governance & $\begin{array}{c}\text { Política Executiva, } \\
\text { Políticas Públicas e } \\
\text { Administração }\end{array}$ & 3 \\
\hline $\begin{array}{l}\text { Canadian Public } \\
\text { Administration }\end{array}$ & $\begin{array}{l}\text { Adm. Pública e } \\
\text { Ciência Política } \\
\end{array}$ & 2 \\
\hline Politologija & $\begin{array}{l}\text { Ciência Política } \\
\text { e Relações } \\
\text { Internacionais }\end{array}$ & 2 \\
\hline Public Administration & $\begin{array}{l}\text { Adm. Pública, } \\
\text { Gestão Pública e } \\
\text { Políticas Públicas }\end{array}$ & 2 \\
\hline Acta Politica & Ciência Política & 1 \\
\hline $\begin{array}{l}\text { Commonwealth \& } \\
\text { Comparative Politics }\end{array}$ & $\begin{array}{c}\text { Política Comparada } \\
\text { e Relações } \\
\text { Internacionais } \\
\end{array}$ & 1 \\
\hline $\begin{array}{l}\text { Public Administration } \\
\text { Review }\end{array}$ & Adm. Pública & 1 \\
\hline Public Management & Gestão Pública & 1 \\
\hline $\begin{array}{l}\text { Revista Uruguaya de } \\
\text { Ciencia Política }\end{array}$ & Ciência Política & 1 \\
\hline $\begin{array}{l}\text { Revue française } \\
\text { d'administration publique }\end{array}$ & $\begin{array}{l}\text { Adm. Pública e } \\
\text { Políticas Públicas }\end{array}$ & 1 \\
\hline $\begin{array}{l}\text { Social and Economic } \\
\text { Studies }\end{array}$ & $\begin{array}{c}\text { Estudos Sociais e } \\
\text { Econômicos }\end{array}$ & 1 \\
\hline $\begin{array}{l}\text { The Economic and Labour } \\
\text { Relations Review }\end{array}$ & $\begin{array}{c}\text { Economia } \\
\text { e Relações } \\
\text { Trabalhistas }\end{array}$ & 1 \\
\hline The Political Quarterly & $\begin{array}{l}\text { Ciência Política e } \\
\text { Políticas Públicas }\end{array}$ & 1 \\
\hline $\begin{array}{l}\text { The Australian Journal of } \\
\text { Public Administration }\end{array}$ & $\begin{array}{l}\text { Adm. Pública, } \\
\text { Gestão Pública e } \\
\text { Políticas Públicas }\end{array}$ & 1 \\
\hline \multicolumn{2}{|l|}{ Total } & 35 \\
\hline
\end{tabular}

Fonte: Elaborado pelo autor.

A publicação nos outros quatorze periódicos ocorreu de forma pouco concentrada, sendo observadas três publicações na Governance, duas publicações na Canadian Public Administration, na Politologija e na Public Administration, e a quantidade de apenas uma publicação nas demais. Tal como notado nos dois casos com maior concentração, foi possível discernir que a grande maioria das revistas possuem como orientação uma perspectiva de pesquisa internacional, ou seja, tendo como orientação examinar distintos países, e abrangendo a preocupação da comparação entre diferentes sistemas como modo profícuo de investigação acadêmica. Além disto, nota-se a participação de periódicos regionais com o mesmo entendimento, aumentando a cobertura empírica e a discussão internacional, como o The Social and Economic Studies sobre a região do Caribe, o The Political Quarterly sobre o Reino Unido e a Revista Uruguaya de Ciencia Política sobre o Uruguai.

Ao considerar os estudos por meio das áreas dos periódicos, por sua vez, foi evidenciado a presença de áreas diversas, como Relações Internacionais, Políticas Públicas, Política Comparada e Gestão Pública, denotando a riqueza da utilização da teoria devido a articulação em várias áreas e sub-áreas. Como ponto em comum, nota-se a interseção frequente entre a Administração Pública e a Ciência Política, a qual compõe o entendimento das instituições e serviços públicos por meio de sua "ciência mãe", tal como refletido por Guy (2003) ao notar o desenvolvimento histórico da primeira como disciplina autônoma no seio da segunda. Dessa forma, nota-se o entrelaçamento de áreas como benéfico tendo em vista abranger as influências e relações com o sistema político e não se limitar aos aspectos técnicos e gerenciais.

A fim de analisar os contextos estudados, faz-se necessário primeiramente examinar as perspectivas por meio das quais as barganhas foram estudadas. Destaca-se que as barganhas governamentais têm sido estudadas em perspectiva nacional, com quatorze estudos (38\%), nacional comparada, com onze estudos (30\%), estadual, com dois estudos (5\%), local, com um estudo (3\%), regional, com cinco estudos $(13 \%)$, referente a um estado soberano, com três estudos $(8 \%)$, e a uma região administrativa, com um estudo (3\%). Nota-se, assim, que a temática tem sido examinada predominantemente em perspectiva nacional, seguida dos estudos que utilizaram a comparação entre vários contextos nacionais. A investigação do governo local e estadual, assim, encontram-se reduzidos nesta temática.

A partir da divisão em perspectivas, identificou-se a baixa concentração em países individuais, sendo a máxima a de dois, como os sobre à Nova Zelândia (LODGE; GILL, 2011; WALLIS, 2010) e à Lituânia (KAZAKEVICIUS, 2014; 2015). Quanto aos estudos comparados, por sua vez, percebe-se a ausência do ano de 2006 a 2011, despontando apenas a partir do ano de 2012 com Lodge e Hood (2012). Dessa forma, foi identificado que antes de se abordar vários contextos comparativamente, foiinvestigado as barganhas políticoadministrativas particulares de países, regiões e de um 
estado soberano, sendo entendido este movimento como oportuno ao permitir o aprofundamento anterior em casos específicos. $\mathrm{Na}$ distribuição da perspectiva comparada, por sua vez, predominou a presença de países desenvolvidos da OCDE (Organização para a Cooperação e Desenvolvimento Econômico), com nove de dez estudos. Esta concentração pode ser compreendida, como mencionado por Hansen, Steen e Jong (2013), por estes países serem exemplos representativos de diferentes tipos de barganha (agência e curadoria) e de reformas administrativas implementadas, sendo oportuno, assim, para o estudo comparativo do papel nestas transformações dos motivos e interesses estratégicos dos servidores e do sistema político em cena.

Considerando todas as perspectivas, percebe-se que apenas sete estudos (19\%) romperam a predominância norte-americana e europeia na utilização da teoria, sendo dois sobre a América Central (LODGE; STIRTON, 2009; LODGE; STIRTON; MOLONEY, 2015), três quanto à Oceania (LODGE; GILL, 2011; WALLIS, 2010; LODGE; HOOD, 2012), um referente à América do Sul (RAMOS; SCROLLINI, 2013) e um sobre Hong Kong (BURNS; WEI; PETERS, 2012). Isto pode ser explicado pela gênese e pelos desenvolvimentos posteriores. Hood (2000; 2001; 2002) e Hood e Lodge (2006) documentaram especialmente as barganhas do Reino Unido e da Alemanha, dando os pesquisadores seguintes ênfase no contexto Anglo-Saxão e em parte da Europa Continental, ou seja, em países democráticos do ocidente que possuíam anteriormente um serviço público forte e desenvolvido. Desta forma, a despeito de comporem diferentes formas de barganhas e reformas gerenciais, notam-se maiores semelhanças institucionais que dão base a compreensão comparativa do que, por exemplo, com o sistema de espólio da América Latina. Assim, a integração da Barganha do Serviço Público para a compreensão de outras conjunturas, como o de países em desenvolvimento com uma administração pública de formação recente e marcada pela forte influência política, como os mencionados, é uma corrente minoritária e ainda em maturação.

\section{Características Metodológicas}

Dos 37 estudos selecionados, nove são teóricos (25\%) e vinte e oito são empíricos $(75 \%)$. Destes, doze são qualitativos (43\%) e quatorze são mistos (57\%), estes utilizando métodos qualitativos e quantitativos de coleta e análise dos dados. Ao notar a ausência de estudos somente quantitativos, demonstra-se o entendimento da interseção entre Ciência Política e Administração, ou seja, dentro de uma ótica interpretativa e histórica em detrimento da correlação de estatística de variáveis e da noção de leis causais das ciências naturais. Dessa forma, foi percebido a utilização de métodos mistos como forma de reforçar a validade interna das análises (SALOMONSEN; KNUDSEN, 2011) e complementar os dados qualitativos ao permitir a comparatividade dos diferentes tipos de dados.

Figura 2 . Tipo e Natureza das Pesquisas

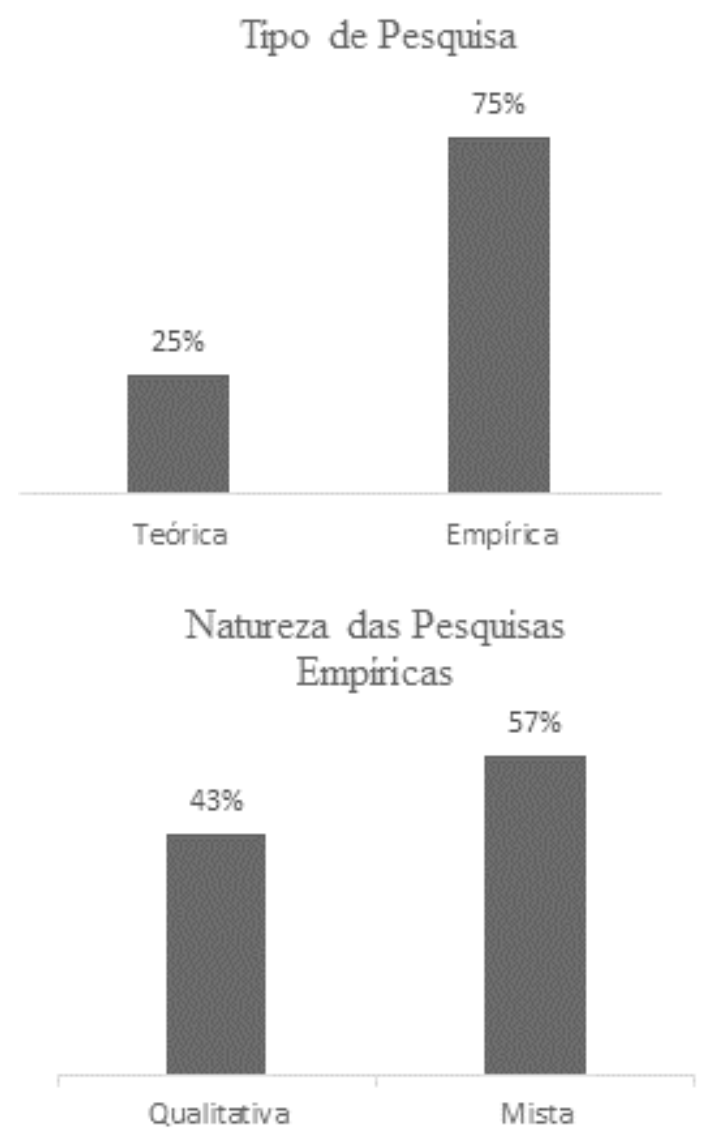

Fonte: Elaborado pelo autor.

Quanto aos estudos empíricos, destaca-se a unidade de análise institucional como dominante, buscando-se a análise do sistema político-administrativo como um todo, seja em nível nacional, comparativo, estadual, local, dentre outros. Por outro lado, foi observada a utilização da unidade organizacional em um estudo e de uma classe específica de servidores em outro. A predominância na unidade institucional explicase no foco dado pela teoria em um olhar holístico, 
ou seja, a interface governamental é estudada como forma de entender as instituições públicas por meio das configurações históricas, estruturais e as relações de poder na qual estão inseridas. Dessa forma, percebe-se que até mesmo os poucos estudos que não utilizaram a unidades de análise institucional buscaram ligações com o sistema político-administrativo mais geral do contexto analisado, visto estarem atreladas as configurações de um ente político determinado, resgatando o entendimento de Hood (2000; 2001; 2002).

Quanto aos recortes temporais, os estudos empíricos dividem-se em longitudinais, em que os dados empíricos são coletados em mais de um período, com quatorze estudos (50\%), e a outra metade em transversais com perspectiva longitudinal, também com quatorze estudos, sendo os dados empíricos coletados em um único momento, mas contendo a noção de mudança ao longo do tempo. A noção das heranças político-administrativas como fator de influência nas formas contemporâneas é ponto de partida de qualquer estudo que utiliza a Barganha do Setor Público (HOOD; LODGE, 2006), explicando assim a coleta de dados primários em mais de um período ou simplesmente o contraste de momentos anteriores por meio de dados bibliográficos e a coleta primária em um momento posterior.

Quanto às fontes de dados utilizados, foi identificado a utilização de fontes primárias em 4 estudos, de fontes secundárias em 7 estudos e dos dois tipos de fontes em conjunto em 17 estudos. Em relação às fontes primárias das pesquisas, nota-se a participação de entrevistas em $64 \%$, principalmente as de natureza semiestruturada, e de questionários em 54\%, sobretudo na forma fechada e com a utilização de escalas. Em relação as fontes secundárias, por outra via, notou-se sobretudo o uso de documentos oficiais, como leis, regulamentos e relatórios governamentais, e sendo percebido a participação de dados históricos em $35 \%$ das pesquisas, abrangendo também jornais e livros de memórias. De forma minoritária, identificouse o uso de dados biográficos provenientes de portais da internet. Foi concluído que os dados secundários têm sido utilizados predominantemente tendo em vista analisar os aspectos formais e históricos das barganhas, sendo auxiliado, por outro lado, pela utilização das fontes primárias na percepção de um cenário mais amplo, incluindo um aprofundamento na consideração dos fatores contextuais e dos aspectos informais.
Os estudos carecem de explicações detalhadas quanto à abordagem epistemológica e ao processo de análise dos dados, notando-se algumas referências breves a "análises interpretativas" ou "explicativas". A despeito disto, constatou-se predominantemente um processo interpretativo de análise na medida em que vários autores ressaltaram a subjetividade, os valores, as crenças e as interpretações dos servidores públicos como modo de compreensão das relações governamentais. Nota-se, por exemplo, o estudo Elston (2017), o qual seguiu uma lógica etnográfica na pesquisa de campo tendo em vista entender a visão de mundo dos sujeitos e limitar os pré-condicionamentos do pesquisador. Quanto aos métodos quantitativos, evidencia-se no conjunto de estudos a utilização de análises estatísticas simples, como se apresenta no estudo de De Visscher e Randour (2014), envolvendo o cálculo de frequências, médias e desvio padrão, e sendo utilizado como forma de aumentar a representatividade dos governos estudados ao facilitar a abrangência de mais sujeitos de pesquisa e se apropriar dos benefícios provenientes da comparatividade de diferentes tipos de dados.

Destaca-se que a maioria dos estudos, dentro do âmbito nacional, focalizam a interface governamental como a relação entre o executivo político, na figura do ministro ou chefes de departamento (departament heads), e membro de altas carreiras do sistema administrativo que existem abaixo do gabinete ministerial. Ampliando o entendimento para o nível local, Siegel (2015), em um trabalho teórico, argumentou para a importância da análise das barganhas no contexto municipal canadense. Empiricamente, contudo, notou-se apenas o estudo de Weiss (2016), o qual analisou a interface no governo local alemão.

\section{Características Teóricas}

Nas pesquisas revisadas, tanto teóricas quanto empíricas, percebe-se o foco central no tema das mudanças político-administrativas decorrentes das reformas administrativas recentes, ou seja, oriundas do movimento da New Public Management (NPM). Esta grande temática está vinculada ao interesse em compreender, no contexto da crise financeira mundial, as pressões exercidas sobre a administração pública e as estruturas governamentais. Neste movimento, destacase que a maioria dos estudos contempla a análise da herança histórica das relações político-administrativas, apoiando-se no entendimento de Hood (2000; 2001; 
2002) de que as transformações são condicionadas, de certa forma, pela inércia histórica e pelos motivos e oportunidades que determinada estrutura possui para o sistema político e o serviço público. Assim, notase que o estudo das reformas administrativas por esta abordagem orienta-se para ir além dos aspectos técnicos e gerenciais, contemplando neste intento a interação estratégica entre os atores e os impactos das transformações nas configurações institucionais e nas relações de poder.

Ao subsidiar o exame das reformas das últimas décadas, a maioria dos estudos abrange o exame amplo dos sistemas político-administrativos, envolvendo a análise das formas específicas de estruturação dos tipos de barganhas operante e das três dimensões que compõe a essência da interface governamental, além de conceber a influência dos tipos sob as dimensões. Quanto às variáveis ou categorias utilizadas na análise das barganhas do serviço público, de forma geral, percebe-se a utilização das sumarizadas na Tabela 1 :

Quadro 1. Variáveis das barganhas do serviço público

\begin{tabular}{|l|l|}
\hline $\begin{array}{l}\text { Tipos e } \\
\text { Dimensões }\end{array}$ & Variáveis \\
\hline Agência & Relação Hierárquica \\
\hline Curadoria & Valores de Orientação \\
\hline Recompensa & Permanência e Risco de Demissão \\
\cline { 2 - 2 } & $\begin{array}{l}\text { Sistema de Carreira no Nível } \\
\text { Individual. }\end{array}$ \\
\cline { 2 - 2 } & Seleção, Indicação e Mobilidade \\
\cline { 2 - 2 } & Montante Salarial e Componentes \\
\hline Competência & Educação e Treinamento \\
\cline { 2 - 2 } & $\begin{array}{l}\text { Assessoria nas Políticas vs. Função de } \\
\text { Entrega }\end{array}$ \\
\cline { 2 - 2 } & $\begin{array}{l}\text { Habilidades Técnicas vs. Habilidades } \\
\text { Gerenciais }\end{array}$ \\
\cline { 2 - 2 } & Motivação do serviço público \\
\hline Lealdade ou & A quem \\
\cline { 2 - 2 } Responsabilidade & Sistema de desempenho individual \\
\cline { 2 - 3 } & Filiação Política \\
\cline { 2 - 2 } & $\begin{array}{l}\text { Evitar a Culpa vs. Reivindicar o } \\
\text { Crédito }\end{array}$ \\
\hline
\end{tabular}

Fonte: Elaborado pelo autor.

O estudo de Van Dorpe e Horton (2011) sobre o Reino Unido é ilustrativo quanto às interpretações históricas como elemento antecedente e aglutinador das variáveis teóricas. Utilizando a imagem clássica do serviço civil daquela nação, a barganha schafferiana, os autores caracterizaram a dimensão recompensa pela entrada jovem no serviço público, a permanência vitalícia no cargo, no salário modesto quando comparado com o setor privado e a promoção por antiguidade e mérito; a dimensão competência envolvia a demanda pela formação generalista em Oxford ou Cambridge, sobretudo em História ou em estudos clássicos, sendo o treinamento realizado pela prática no trabalho e na ênfase das habilidades técnicas; e a lealdade ou responsabilidade estruturada por um sistema de mérito, o caráter de anonimato e o não-partidarismo. Em contraste com este sistema, o qual possui certa independência do sistema político ao estar vinculado as leis e a família real, semelhante a países anteriormente pertencentes ao Império Britânico, como o Canadá, a Nova Zelândia e a Austrália, outros países caracterizavam-se por certa liberdade apoiada pelo pacto no seio do Estado de variadas partes étnicas, religiosas e linguísticas da sociedade, como a Holanda e a Bélgica.

Apoiada neste entendimento das barganhas tradicionais, a mudança para um sistema gerencial foi investigada pela ênfase deste em um maior controle da sociedade e dos políticos eleitos sobre o serviço público, ou seja, pela hipótese da mudança para maior participação da subordinação hierárquica como critério de orientação da administração pública. Neste sentido, foi notado a operacionalização das categorias teóricas pelos seguintes temas: planejamento estratégico, sistema de controle de desempenho, mudança e resistência cultural e fatores demográficos e ambientais. Weiss (2016), por exemplo, utilizou como ponto focal, em governos locais da Alemanha, o que era dado e recebido em contrapartida pelos atores governamentais nos dilemas de implementação dos planejamentos estratégicos, tendo em vista que este processo envolvia ganhos e perdas para os dois atores em cena. Hondeghem e Van Dorpe (2012), por outro lado, analisaram os sistemas de controle de desempenho de vários países da OCDE comparativamente como forma de examinar o nível das mudanças para a lógica gerencial nos contextos estudados.

O papel dos fatores culturais foi incorporado, por exemplo, por Salomonsen e Knudsen no contexto holandês, Kazakevecivius (2014; 2015) sobre a Lituânia e por Ramos e Scrollini (2013) sobre o contextolatino americano. Enquanto que no primeiro caso os fatores culturais foram mobilizados tendo em vista as 
mudanças ocorridas nestes nas décadas de 1960 e 1970 na Holanda pela transformação do perfil educacional dos servidores e da interpretação dos respectivos papéis na administração pública, no segundo caso foi mobilizada como elemento de resistência tendo em vista os valores culturais mais gerais da sociedade. No contexto latino-americano, por outro lado, a resistência cultural foi mobilizada a fim de incorporar o papel da forte tradição da troca de cargos por apoio político que inibe em certo nível o movimento de instituição de uma burocracia mais autônoma do controle político personalista ou partidário. Nota-se nos dois últimos contextos, sendo o primeiro de um país pós-comunista do leste europeu e o segundo sobre dois países latino-americanos, o contraste com outros países investigados, sendo investigado o movimento de instituição de um controle hierárquico delegado por metas e objetivos em contraste com um controle hierárquico com forte influência político-partidário do sistema de espólio, a patronagem.

Ao encarar questões mais gerais de investigação das categorias teóricas presentes no Quadro 1, observase, por exemplo, o trabalho de Kazakevicius (2014), o qual investigou o nível da influência política, denominado como politização, a fim de investigar o compromisso ou modo que a lealdade é pactuada na administração federal da Lituânia. Fleischer (2016), sobre os servidores federais da Alemanha, por sua vez, investigou a permanência ou não nos altos cargos por meio da influência das lealdades políticas e das retribuições monetárias.

Além disso, foi identificado que muitas variáveis destacam-se por não serem de fácil captura, não raro sendo omitidas pelos sujeitos de pesquisa, como a filiação política. Como forma alternativa, os pesquisadores têm utilizado documentos oficiais, dados de anuários e dados biográficos disponíveis na internet, como realizado por Steen e Van der Meer (2011). Outra dificuldade é a presença de elementos subjetivos, notando-se a utilização, como estratégia de pesquisa, de perguntas semiestruturadas ou abertas a fim de permitir a livre expressão dos atores governamentais, e, por meio de uma abordagem interpretativa, analisar as crenças e valores dos sujeitos. Isto tem sido adotado, além disto, como forma de se ir além dos aspectos explícitos e formais, captando-se os elementos implícitos das barganhas.

\section{Rompendo os Limites}

Outros estudos, sobretudo teóricos, têm dado atenção para elementos não abrangidos inicialmente, seja por Hood e Lodge (2006), seja pelo foco da maioria das investigações. Buscando-se, dessa forma, romper os limites presentes, tem sido argumentado e analisado a necessidade de se pensar as interfaces governamentais por meio de outros atores, aspectos e temáticas.

Quanto aos atores, destacam-se as análises sobre os assessores ou conselheiros especiais (special advisers) de Shaw e Eichbaum (2017) e Connaughton (2017). Tendo como base que, na contraposição entre a competência neutra e a responsiva (ABERBACH; ROCKMAN, 1994), os assessores especiais caracterizam-se como responsivos, ou seja, como confidentes do sistema político, presume-se outra lógica nas barganhas entre um ministro, como executivo político, e um assessor especial do que o presente entre aquele e um alto servidor de carreira. Nesta tripla relação, os pesquisadores têm investigado o papel do assessor especial e sua influência nas relações governamentais do poder executivo.

Em uma linha minoritária de estudos, destaca-se o uso de conceitos como patrimonialismo, patronagem, politização, colonialismo, transplantação de instituições, herança e resistência cultural. Quanto aos dois primeiros, Ramos e Scrollini (2013) analisam a administração pública no Chile e Uruguai tendo como fundamento que na América Latina a patronagem é uma característica central, contrastando, assim, o impacto das reformas do serviço civil sobre o sistema patronal e a forte politização anterior. Quanto aos outros conceitos, destaca-se o estudo de Lodge, Stirton e Moloney (2015), os quais analisam a influência colonial e cultural da região do Caribe em contraponto à transplantação de instituições e práticas do Reino Unido. De forma semelhante, Burns, Wei e Peters (2012) analisam as mudanças e continuidades em um contexto pós-colonial, Honk Kong, por meio da conexão entre mudanças empreendidas e as resistências oriundas da herança histórica e cultural.

\section{Principais Resultados Empíricos}

\section{Barganhas Nacionais}

Ao analisar os resultados dos estudos em âmbito nacional, foi verificado a mudança parcial para a subordinação gerencial e para a visão individualista 
de diferentes formas. Na Bélgica (DE VISSCHER et. al, 2011) e na Holanda (STEEN; VAN DER MEER, 2011), tendo como antecedente a mistura entre a barganha representacional e a lealista periódico na década de 1970, e dentro de uma visão hierárquica, identificou-se o aumento da delegação gerencial em detrimento das clivagens sociais como fonte de autonomia e poder, compondo, por outro lado, uma barganha "híbrida", ou seja, comportando uma mistura entre as antigas barganhas e as novas. Neste movimento, notou-se no caso belga a flexibilização da permanência por contratos temporários, o aumento da demanda por entrega de resultados em conjunto com as habilidades técnicas, e a mistura entre lealdades partidárias e quanto aos acordos de desempenho; e, no caso holandês, o pagamento por desempenho, a demanda pelas habilidades gerenciais em conjunto com as técnicas e as de negociação, e a lealdade passou a ser pactuada pela mesma visão quanto às políticas públicas, em relação ao acordo de desempenho e as vinculações partidárias.

De modo convergente com estes países, Halligan (2013) nota mudanças para a visão individualista no Canadá, também não comportando uma transformação radical em relação as barganhas antecedentes. Nesta entendimento, os autores destacam o papel da governança multi-level composta pelos processos de privatização, agencificação, desregulamentação, descentralização territorial, desconcentração e o maior envolvimento dos cidadãos e da sociedade civil. Dessa forma, o sistema político abre mão do poder de controle em troca da possibilidade de reivindicar crédito sobre o sucesso das políticas e evitar a culpa ao dar mais autonomia e visibilidade aos gerentes. Não obstante, como argumentado por Van Dorpe e Horton (2011), nota-se o aumento do número de chefes executivos nas agências e assessores ou conselheiros especiais nos departamentos desde a década de 1980 como forma de manter a influência política, sendo estes temporários e sob indicação. Além disso, Steen e Van Deer Meer (2011), em referência a um argumento semelhante ao de Maor (1999), mencionam as reformas gerenciais como forma de aumentar o controle sobre os servidores e diminuir a autonomia destes. Embora note-se a complexidade deste argumento, a erosão da permanência dos servidores acompanhada de uma delegação complexa, ou seja, em que a delegação é acompanhada por um principal político auxiliar, demonstra a possibilidade interpretativa neste sentido.
Quanto às mudanças nas barganhas em perspectiva nacional, destaca-se o estudo de Salomonsen e Knudsen (2011), os quais, ao questionar como a Holanda transformou-se da curadoria das décadas de 1960 e 1970 para modos mais responsivos perante o comando político, notaram o papel da informalidade na tradição político-administrativa naquele ente político, tendo os servidores reinterpretado as atribuições que desempenhavam de modo a maximizar os próprios interesses, e, assim, adentrar de forma mais forte na arena do aconselhamento político, em conformidade com um ambiente cultural que cada vez mais passou a reconhecer este papel como legítimo. Dessa forma, os autores perceberam que os elementos exógenos de transformação das barganhas eram, de alguma forma, incorporados de acordo com os interesses institucionais do serviço civil, destacando, ademais, os interesses profissionais destes atores, os quais emergiram como fenômeno relevante ao ser verificado a mudança para perfis com maior formação educacional.

Em relação as outras perspectivas, por sua vez, Van Dorpe e Horton (2011), analisando o Reino Unido, notaram que a influência gerenciou findou o caráter de autoabnegação dos servidores quanto a remuneração monetária devido ao aumento dos salários que acompanhou a política de pagamento por desempenho. Além disso, os autores destacam o aumento da valorização das competências de execução e de negociação, além de comportar a pactuação de um compromisso mais limitado quando comparado com o anterior que possibilitava servir sucessivos políticos eleitos. Os autores destacam também o aumento do número de assessores especiais no governo thatcheriano como forma do sistema político aumentar a influência sobre a implementação das políticas públicas.

\section{Barganhas Comparadas}

Por meio da análise, em um mesmo estudo, de casos nacionais de diferentes países e regiões, compõe-se a perspectiva comparativa, utilizada como modo de entender as respostas institucionais que diferentes sistemas políticos manifestaram às pressões recentes exercidas no contexto mundial. Neste ensejo, Lodge e Hood (2012), ao analisar as pressões advindas das crises financeiras em conjunto com os fatores ambientais e demográficas em países da OCDE, notou diferentes reações institucionais, tendo como explicação as 
diferentes vulnerabilidades dos respectivos países. Assim, a despeito de pressões de homogeneização, como o capitalismo global e as tecnologias comuns, os autores percebem diferentes pressões reformistas, culturas e sistemas corporativos, os quais influenciam as mudanças governamentais.

Por outro lado, Hondeghem e Van Dorpe (2012), investigam o nível gerencial de membros da OCDE por meio do controle de resultados dos respectivos sistemas gestão de desempenho. Enquanto no Reino Unido verificou-se um forte nível de controle em todo ciclo de gestão, com objetivos claros e quantificáveis, na Holanda foi observado um nível médio, sendo mais informal e pouco transparente. Os autores interpretaram esta variação na maior força dada as reformas nos casos anglo-saxões do que em pequenos países da Europa, estando vinculado, naqueles, a sistemas de remuneração e a forma como encaram o comportamento humano nas organizações. Além disso, ao identificarem menor controle gerencial sobre os servidores na Dinamarca, onde há uma tradição de cooperação político-administrativa com os ministros, são fortalecidas as inferências de outros estudos que atribuem às reformas, de certa forma, um meio de quebrar os controles burocráticos e substituí-los por maior controle político.

Quanto às barganhas triplas, entre o executivo político (ministros), assessores especiais e altos servidores públicos, De Visscher e Salomonsen (2012) verificaram que na Dinamarca há um relacionamento complementar e cooperativo entre as partes, havendo poucos assessores, e sendo a maioria de jornalistas instruídos e subordinados aos servidores. $\mathrm{Na}$ Bélgica, em contrapartida, percebe-se o grande número de assessores especiais trabalhando como confidente do ministro, e expressando uma politização ampla em todos os ciclos de políticas públicas. Neste caso, os autores percebem a perda de poder dos altos servidores perante as competências, fidelidades e recompensas pactuadas, bem como maior nível de conflito, desconfiança e trapaça (cheat) entre os atores. Destaca-se a importância deste estudo ao explorar empiricamente a relevância em se pensar em novos atores que perfazem as relações político-administrativas.

\section{Barganhas em Outros Contextos}

A utilização do framework de Hood e Lodge (2006) para contextos pós-coloniais, pós-comunistas e caracterizados pela patronagem tem sido orientada de forma distinta que as vertentes anteriores. Kazakevicius (2014; 2015), por exemplo, analisou a Lituânia, país pós-comunista do leste europeu, observando a carência de uma cultura clara quanto ao relacionamento político-administrativo e a falta de confiança mútua. No contexto das pressões de austeridade, sobretudo com a influência da crise mundial de 2008, o autor observou que a lógica individualista, baseada no maior controle hierárquico dos políticos, na remuneração por desempenho e na flexibilização da permanência no cargo, foi menos influente na Lituânia que em outros sistemas políticos, interpretando nisto a força do valor igualitário vigente, com limites para a utilização da remuneração como modo de incentivo e contrapartida e a ação organizada dos servidores em cortes e tribunais a fim de defender a posição, o modo de remuneração e a autonomia dos servidores.

De outra forma, nota-se uma mudança maior da curadoria para a agência no caso de Honk Kong, em sua passagem institucional de colônia para região administrativa, notando-se maior controle por parte do executivo político sobre os servidores. Burns, Wei e Peters (2012) analisaram este movimento das barganhas governamentais por meio da diminuição dos salários e aposentadorias, os quais passaram a ser mais semelhantes com o do setor privado, a criação de um cargo político entre o executivo político e os altos servidores, o qual passou a exercer forte controle perante estes, e a composição de perfis mais voltados à entrega de resultados. Ademais, a partir dos achados, os autores contestaram o pressuposto da necessidade de estabilidade das expectativas dos dois atores perante a natureza dos papéis recíprocos, sendo a fluidez e a instabilidade proveniente das mudanças institucionais e políticas respondidas pelos servidores e agentes políticos na reorganização das barganhas em prol de alcançar a governança, mas não sem disputas e resistências, notando-se a reação dos servidores ao contexto e ao assumirem papéis políticos quando interpretaram necessário em certas situações.

Quanto a outros contextos pós-coloniais, a Jamaica e outras ilhas caribenhas, Lodge, Stirton e Moloney (2015) notaram a doutrina da curadoria como forma que a Coroa britânica manifestava seu modo de administrar a colônia, o "governar um país para o benefício de seu povo", sendo, contudo, alvo de críticas visto a baixa remuneração dos servidores públicos e a falta de interesse em desenvolver a 
competência administrativa colonial. Além disto, os autores perceberam que a fidelidade dos servidores públicos perante o comando político não era um elemento de tensão, sendo explicado, possivelmente, pelo insulamento dos servidores perante as lideranças políticas locais, e colocando-se como lacuna a compreensão de a quem eram leais, ao governo imperial ou à população em geral.

No contexto latino-americano, Ramos e Scrollini (2013) analisaram a herança do sistema da patronagem e a respectiva influência nas barganhas políticoadministrativas do Chile e do Uruguai em contraponto com as reformas empreendidas no bojo da New Public Management, sobretudo na forma da criação da carreira de Autos Dirigentes Públicos e dos contratos de desempenho estabelecidos entre os servidores dos ministérios e agências perante os Ministros de Estado. As reformas foram mobilizadas nos dois países tendo em vista desenvolver o caráter gerencial de seus sistemas administrativos e diminuir a politização do serviço civil, tendo sido alcançado apenas de forma parcial, convivendo-se com a herança ainda persistente da patronagem (RAMOS; SCROLLINI, 2013).

\section{Conclusões e Proposta de Agenda de Pesquisa}

Conclui-se que o relacionamento entre os atores políticos e administrativos é multifacetado, concorrendo diversos fatores e elementos, muitos ainda não incorporados empiricamente. Resultados convergentes e divergentes expressam diferentes tradições históricas, vulnerabilidades, oportunidades e interesses dos atores em ação em cenários específicos. Destaca-se quanto às divergências e perplexidades de certas pesquisas, que, ao contrário de se abordar a Barganha do Serviço Público como teoria acabada, percebe-se o movimento de estudiosos de países e regiões diversas em desenvolvê-la ao contrastá-la com achados empíricos divergentes, assuntos relevantes não abordados inicialmente, e o aumento progressivo notado na presença de assessores especiais e a participação de outros atores e arenas importantes.

A pequena expressividade de pesquisas que contemplem países fora do eixo anglo-saxão e europeu demonstra a oportunidade de se abordar o contexto da América Latina e, em específico, do governo brasileiro. Quanto a este, de modo similar ao situado por Ramos e Scrollini (2013) sobre o Chile e Uruguai, torna-se preponderante refletir sobre as influências do sistema de patronagem que caracteriza a interface governamental brasileira (GRINDLE, 2012), e, particularmente, em contraponto as reações institucionais empreendidas. Investigações históricas que utilizaram o framework de Hood e Lodge (2006) têm destacado a relevância analítica deste no entendimento das mudanças e continuidades, como apontado por Ongaro e Bellé (2009) ao examinar os movimentos que deram ensejo a remuneração por resultado na Itália.

A análise da reforma administrativa implementada no governo federal brasileiro na década de 1990 sob o prisma das dimensões competência, recompensa e lealdade se apresenta como modo oportuno de se examinar as mudanças empreendidas e as que não obtiveram sucesso por meio dos interesses e oportunidades envolvidas dos políticos e administradores públicos em cena. Ao notar, de certa forma, um ressoar da ênfase gerencial no contexto da crise fiscal e de governabilidade iniciada no ano de 2014, incorporar esta abordagem pode contribuir para se clarear e antever as propostas e mudanças recentes.

Por outro lado, contemplar o tema das reformas administrativas em nível estadual e municipal apresenta-se como modo oportuno de se avançar na compreensão da administração pública e do governo brasileiro, tendo em vista que estas têm sido implementadas, de alguma maneira, com narrativas semelhantes ao do nível federal. Além disso, a cooperação federativa implica em influências do ente nacional sobre os demais entes federados, tendo o município, por exemplo, a demanda por competências e responsabilidades oriundas direta ou indiretamente de diretrizes ministeriais. Quanto a vertente subnacional, em específico, demonstra-se a relevância particular no estudo de Nigro e Kellough (2008), os quais, ao abordar o contexto estadual norte-americano, analisaram o relatório da agenda de reformas Winter Commission em contraponto as avaliações empíricas posteriores, notando que a narrativa de cooperação, negociação e habilidades foi utilizada largamente como forma de erodir a permanência no cargo dos servidores e dos controles burocráticos e como modo de reforçar a influência política sobre a administração, embora tenha sido considerado certos desenvolvimentos técnico-administrativos. 


\section{Referências}

ABERBACH, J. D.; PUTNAM, R. D.; ROCKMAN, B. A. Bureaucrats and Politicians in Western Democracies. Cambridge, MA: Harvard University Press. 1981.

ABERBACH, J. D.; ROCKMAN, B. A. Civil servants and policymakers: neutral or responsive competence? Governance, v. 7, n. 4, p. 461-469, 1994.

ABRUCIO, F. L. Trajetória recente da gestão pública brasileira: um balanço crítico e a renovação da agenda de reformas. Revista de Administração Pública, v. 41, 2007.

BACH, T.; NIKLASSON, B.; PAINTER, M. The role of agencies in policy-making. Policy and Society, v. 31, n. 3, p. 183-193, 2012.

BURNS, J. P.; WEI, L.; PETERS, B. G. Changing governance structures and the evolution of Public Service Bargains in Hong Kong. International Review of Administrative Sciences, v. 79, n. 1, p. 131-148, 2013

CAVALCANTE, P.; LOTTA, G. (Org.). Burocracia de médio escalão: perfil, trajetória e atuação. Brasília: Enap, 2015.

CONNAUGHTON, B. Political-

administrative relations: The role of political advisers. Administration, v. 65, n. 2, p. 165-182, 2017.

DE ARAÚJO, P. G.; PEREIRA, J. R. Análise da aplicabilidade do modelo gerencial na administração municipal. Revista de Administração Pública, v. 46, n. 5, p. 1179-1199, 2012.

DE VISSCHER, C.; SALOMONSEN, H. H. Explaining differences in ministerial ménages à trois: multiple bargains in Belgium and Denmark. International Review of Administrative Sciences, v. 79, n. 1, p. 71-90, 2013

DE VISSCHER, C.; RANDOUR, F. The reform of the Belgian federal administration 10 years on: what balance has been achieved between operational autonomy of top managers and the supervision carried out by the horizontal ministerial departments? International Review of Administrative Sciences, v. 80, n. 1, p. 33-51, 2014. DE VISSCHER, C., et. al. The changing Public
Service Bargain in the federal administration in Belgium. Public Policy and Administration, v. 26, n. 2, p. 167-188, 2011.

ELSTON, T. Conflict between explicit and tacit public service bargains in UK executive agencies. Governance, v. 30, n. 1, p. 85-104, 2017.

FLEISCHER, J. Partisan and professional control: Predictors of bureaucratic tenure in Germany. Acta Politica, v. 51, n. 4, p. 433-450, 2016.

GOMES, D. P.. A Importância do Critério Partidário como Parâmetro de Seleção dos Dirigentes da Secretaria Federal de Controle Interno. Revista da Controladoria-Geral da União, v. 8, n. 13, p. 447472, 2016.

GRINDLE, M. Jobs for the boys: patronage and the politics of public sector reform. Cambridge: Harvard University, 2012.

GUY, M. E. Ties that bind: The link between public administration and political science. Journal of Politics, v. 65, n. 3, p. 641-655, 2003.

HALLIGAN, J. The evolution of Public Service Bargains of Australian senior public servants.

International Review of Administrative Sciences, v. 79, n. 1, p. 111-129, 2013.

HANSEN, M. B.; STEEN, T.; JONG, M. de. New Public Management, Public Service Bargains and the challenges of interdepartmental coordination: a comparative analysis of top civil servants in state administration. International Review of Administrative Sciences, v. 79, n. 1, p. 29-48, 2013.

HONDEGHEM, A. Changing public service bargains for top officials. Public Policy and Administration, v. 26, n. 2, p. 159-165, 2011.

HONDEGHEM, A.; STEEN, T. Evolving public service bargains for top officials: some international comparisons. International Review of Administrative Sciences, v. 79, n. 1, p. 3-8, 2013.

HOOD, C. Paradoxes of public-sector managerialism, old public management and public service bargains. International Public Management Journal, v. 3, n. 1, p. 1-22, 2000.

HOOD, C. Public Service Bargains and public service reform. In: Peters BG and Pierre J (eds). Politicians, Bureaucrats and Administrative Reform. New York: Routledge, pp. 13-23, 2001 
HOOD, C. Control, bargains, and cheating: The politics of public-service reform. Journal of Public Administration Research and Theory, v. 12, n. 3, p. 309-332, 2002.

HOOD, C.; LODGE, M. The politics of public service bargains: reward, competency, loyalty-and blame. Oxford: Oxford University Press, 2006.

KAZAKEVICIUS, G. Impact of loyalty bargain to the politicisation of the public sector in lithuania. Politologija, v. 2, n. 74, p. 161-197, 2014.

KAZAKEVICIUS, G. Executive's rewards and their changes in the lithuanian public sector. Politologija, v. 1, n. 77, p. 101-151, 2015.

LODGE, M.; GILL, D. Toward a new era of administrative reform? The myth of post-NPM in New Zealand. Governance, v. 24, n. 1, p. 141-166, 2011.

LODGE, M.; HOOD, C. Into an age of multiple austerities? Public management and public service bargains across OECD countries. Governance, v. 25, n. 1, p. 79-101, 2012.

LODGE, M.; STIRTON, L. Beyond the Inherited Model: Public Service Bargains in the Commomwealth Caribbean. Social and Economic Studies, p. 43-67, 2009

LODGE, M.; STIRTON, L.; MOLONEY, K.. Whitehall in the Caribbean? The legacy of colonial administration for post-colonial democratic development. Commonwealth \& Comparative Politics, v. 53, n. 1, p. 8-28, 2015.

LOPEZ, F. G. (Org.). Cargos de confiança no presidencialismo brasileiro. Brasília: IPEA, 2015.

LOUREIRO, M. R.; ABRUCIO, F. L. Política e burocracia no presidencialismo brasileiro: o papel do Ministério da Fazenda no primeiro governo Fernando Henrique Cardoso. Revista Brasileira de Ciências Sociais, v. 14, n. 41, p. 69-89, 1999.

LOUREIRO, M. R.; ABRUCIO, F. L; PACHECO, M. F. Introdução. In: LOUREIRO, M. R.; ABRUCIO, F. L; PACHECO, M. F. (Orgs.) Burocracia e política no Brasil: desafios para a ordem democrática no século XXI. Rio de Janeiro: Editora FGV, 2010

LOUREIRO, M. R.; OLIVIERI, C.; MARTES, A. C. B. Burocratas, partidos e grupos de interesse: o debate sobre política e burocracia no Brasil. In: Burocracia e política no Brasil: desafios para a ordem democrática no século XXI. Rio de Janeiro: Editora FGV, 2010. p. 73-108.

LOUREIRO, M. R. Burocratas e Partidos Políticos na Democracia Brasileira. In: CARDOSO, J. C. J.; BERCOVICI, G. (Orgs.) República, Democracia e Desenvolvimento: contribuições ao Estado brasileiro contemporâneo. Brasília: IPEA, 2013, p. 371-401.

MAOR, M. The paradox of managerialism. Public Administration Review, v. 59, n. 1, jan./feb. , p. 5-18, 1999 .

OLIVEIRA, V. E.; ABRUCIO, F. L. Entre a política e a burocracia: a importância dos burocratas de nível médio para a produção de políticas públicas em saúde e educação. In: ENCONTRO ANUAL DA ANPOCS, 35, 2011, Caxambu. Anais...

OLIVEIRA, C. B. de; FILHO, J. R. F. Problemas de agência no setor público: o papel dos intermediadores da relação entre poder central e unidades executoras. Revista de Administração Pública. Rio de Janeiro, v. 51, n. 4, p. 596-615, jul. ago., 2017.

OLIVIERI, C. Política, Burocracia e Redes Sociais: As nomeações para o alto escalão do Banco Central. Revista de Sociologia e Política, n. 29, nov., 147-168, 2007.

OLIVIERI, C. A lógica política do controle interno: o monitoramento das políticas públicas no presidencialismo brasileiro. Sao Paulo: Ed. Annablume, 2010.

ONGARO, E.; BELLÉ, N. Réforme de la fonction publique et introduction de la rémunération liée aux performances en italie. Revue française d'administration publique, n. 132, p. 817-839, 2010.

PUTNAM, R. D. The Comparative Study of Political Elites. Englewood Cliffs, N.J.: PrenticeHall. 1976.

PRAÇA, S.; FREITAS, A.; HOEPERS, B.. Political appointments and coalition management in Brazil, 2007-2010. Journal of Politics in Latin America, v. 3, n. 2, p. 141-172, 2011.

RAMOS, C.; SCROLLINI, F. Los nuevos acuerdos 
entre políticos y servidores públicos en la alta dirección pública en Chile y Uruguay. Revista Uruguaya de Ciencia Política, v. 22, n. 1, p. 11-36, 2013.

SALOMONSEN, H. H.; KNUDSEN, T. Changes in public service bargains: Ministers and civil servants in Denmark. Public Administration, v. 89, n. 3, p. 1015-1035, 2011.

SCHAFFER, B. The Administrative Factor: Papers in Organization, Politics and Development. London: Cass. 1973.

SHAW, R.; EICHBAUM, C. Politicians, political advisers and the vocabulary of public service bargains: Speaking in tongues? Public Administration, v. 95, n. 2, p. 312-326, 2017.

SIEGEL, D. The "public service bargain" in local government: A new way of looking at relations between municipal councils and CAOs. Canadian

Public Administration, v. 58, n. 3, p. 406-425, 2015.

STEEN, T.; VAN DER MEER, F. Public service bargains in Dutch top civil service. Public Policy and Administration, v. 26, n. 2, p. 209-232, 2011.

SVARA, J. H. Dichotomy and duality:

Reconceptualizing the relationship between policy and administration in council-manager cities. Public

Administration Review, vol. 45, p. 221-232, 1985.

SVARA, J. H. Complementarity of politics and administration as a legitimate alternative to the dichotomy model. Administration \& Society, v. 30, n. 6, p. 676-705, 1999.

TORRES, M. D. F. Estado, democracia e administração pública no Brasil. Rio de Janeiro: Editora FGV, 2004.

VAN DORPE, K.; HORTON, S. The public service bargain in the United Kingdom: The Whitehall model in decline? Public Policy and

Administration, v. 26, n. 2, p. 233-252, 2011.

VERSCHUERE, B.; BACH, T. Executive agencies, ministers, and departments: Can policy and management ever be separated? Administration \& Society, v. 44, n. 2, p. 183-206, 2012.

WALLIS, J. A tale of two leaders: Leadership and cultural change at the New Zealand treasury.

Australian Journal of Public Administration, v. 69, n. 1, p. 22-33, 2010.
WEISS, J. Trust as a key for strategic management? The relevance of council-administration relations for NPM-related reforms in German local governments. Public Management Review, p. 1-16, 2016. 